\title{
Accidental Displacement of Impacted Maxillary Third Molar: A Case Report
}

\author{
Cassio Edvard SVERZUT \\ Alexandre Elias TRIVELLATO \\ Luiz Marcel de Figueiredo LOPES \\ Emanuela Prado FERRAZ \\ Alexander Tadeu SVERZUT \\ Department of Oral and Maxillofacial Surgery and Periodontology, Faculty of Dentistry of Ribeirão Preto, \\ University of São Paulo, Ribeirão Preto, SP, Brazil
}

\begin{abstract}
An unusual case of an impacted right maxillary third molar that was accidentally displaced into the maxillary sinus during exodontia and was surgically retrieved almost 2 years later is described. The tooth was removed under general anesthesia, after maxillary sinus exposure through Caldwell-Luc approach. Postoperative recovery was uneventful. Six months after the retrieval surgery, the maxillary sinus was completely healed and the patient did not present any complaint.
\end{abstract}

Key Words: third molar, intraoperative complications, accidental displacement.

\section{INTRODUCTION}

Removal of impacted maxillary third molars is a common surgical procedure performed by oral surgeons and dentists alike. As expected with any surgical intervention, accidents may occur during exodontia, such as tooth displacement into the maxillary sinus. Although this type of accident has often been mentioned in oral surgery textbooks, very few cases have been reported in the literature $(1,2)$. The presence of a tooth inside the sinus may lead to complications such as infection, and thus its surgical removal is strongly recommended (2). This report describes an unusual case of impacted maxillary third molar that was accidentally displaced into the maxillary sinus during extraction and remained there for almost two years.

\section{CASE REPORT}

An eighteen-year-old Caucasian female patient was referred to the Clinic of Oral and Maxillofacial Surgery of the Faculty of Dentistry of Ribeirão Preto, University of São Paulo, with a complaint of pain in the right infra-orbital area and bad taste on swallowing during the previous two months. The patient reported having the right maxillary third molar surgically extracted by a general dentist nearly two years before. The procedure was described as being complicated, but the professional did not inform the patient of any intraoperative accident. Intraoral clinical examination revealed only absence of the third molars. A panoramic radiograph suggested the presence of a tooth apparently inside the right maxillary sinus (Fig. 1). The panoramic radiograph taken before extraction of the third molars was requested to the patient and helped to confirm the diagnosis of tooth displacement (Fig. 2). Frontal and transverse computed tomography (CT) scans (Figs. 35) were taken to determine the precise position of the tooth in a three-dimensional view. These images showed that the tooth was located approximately in the center of the maxillary sinus. In addition, secretion was observed in the right maxillary, frontal and etmoidal sinuses. Under general anesthesia, the maxillary sinus was exposed through Caldwell-Luc approach showing a large quantity of purulent secretion (Fig. 6). The tooth was removed only by negative pressure of the suction pump (Fig. 7). The sinus was cleaned by intensive irrigation with saline and a meatotomy was performed to enlarge the meatal ostium. The wound was closed with polyglactin 910, and dipyrone (3 g/day), ketoprofen (200 mg/day) and clindamicine (1800 mg/day) were prescribed.

Correspondence: Prof. Dr. Cassio Edvard Sverzut, Departamento de Cirurgia e Traumatologia Buco-Maxilo-Facial \& Periodontia, Faculdade de Odontologia de Ribeirão Preto, USP, Av. do Café, S/N, Monte Alegre, 14040-904 Ribeirão Preto, SP, Brasil. Tel: +55-163602-4083. Fax: +55-16-3633-0999. e-mail:cesve@forp.usp.br 


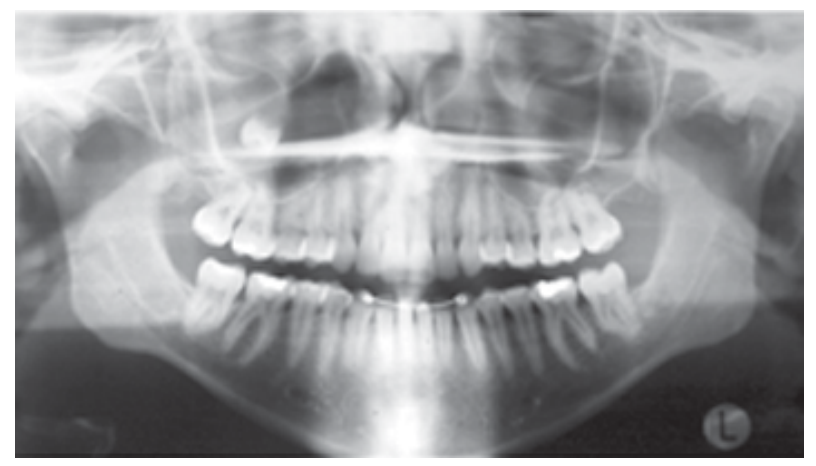

Figure 1. Panoramic radiograph taken at the patient arrival, suggesting the presence of a tooth into the right maxillary sinus.

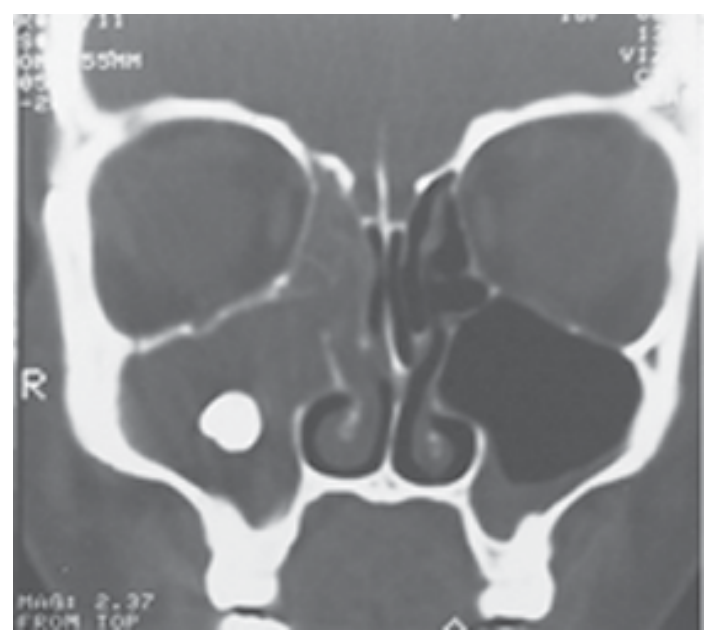

Figure 3. Frontal CT scan showing the vertical position of the tooth inside the maxillary sinus and large amount of secretion in the maxillary sinus and the etmoidal cells.

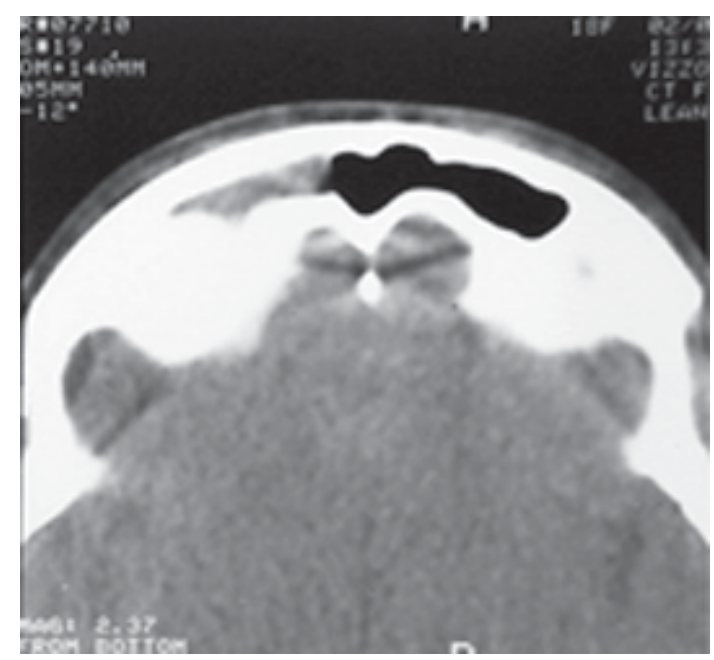

Figure 5. Transverse CT scan showing the presence of secretion inside the right frontal sinus.

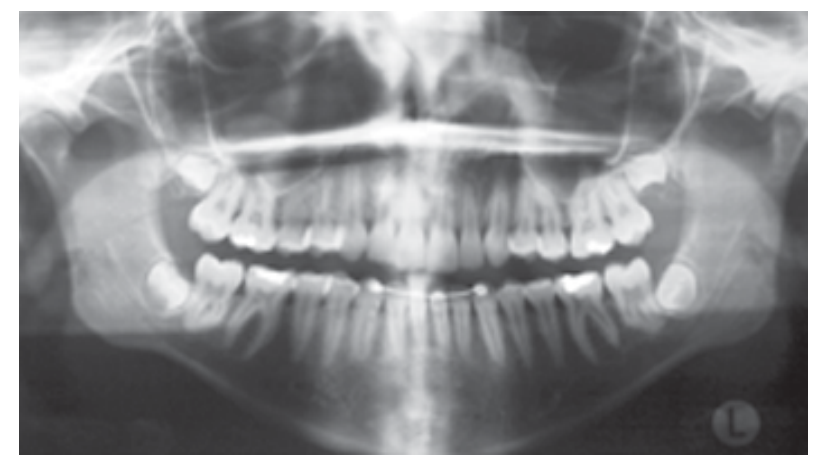

Figure 2. Panoramic radiograph taken before removal of the third molars, confirming the diagnosis of tooth displacement.

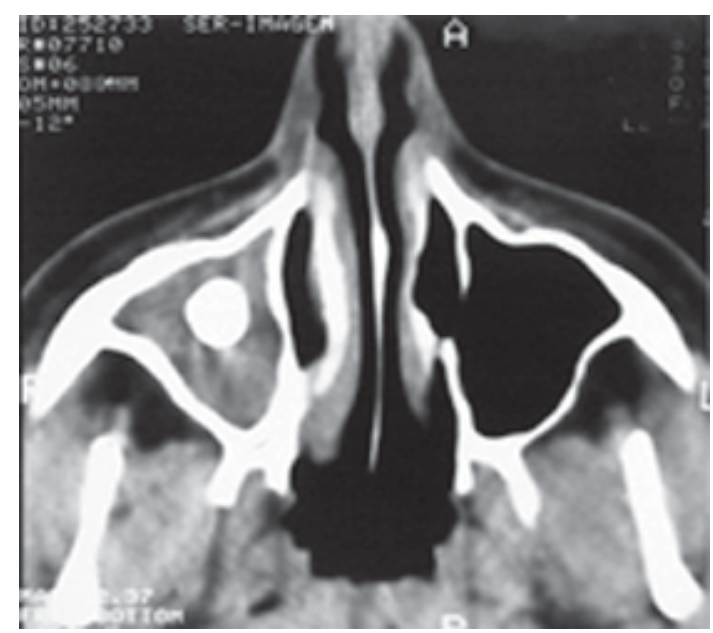

Figure 4. Transverse CT scan showing the antero-posterior position of the tooth inside the maxillary sinus.

Postoperative recovery was uneventful. After 6 months, CT scans showed good healing of the maxillary sinuses (Fig. 8), in spite of bilateral enlargement of the mucosa, and the patient did not present any complaint.

\section{DISCUSSION}

Surgical removal of impacted maxillary third molars is a common procedure routinely carried out in dental offices. Most of these oral surgeries have an orthodontic indication. In some situations, as in the case reported in this paper, the orthodontist wishes to prevent anterior tooth crowding after the orthodontic treatment is completed (3-5). The decision to extract an impacted tooth must be based on careful weighing of potential benefits and risks (3). It is important to confirm the 


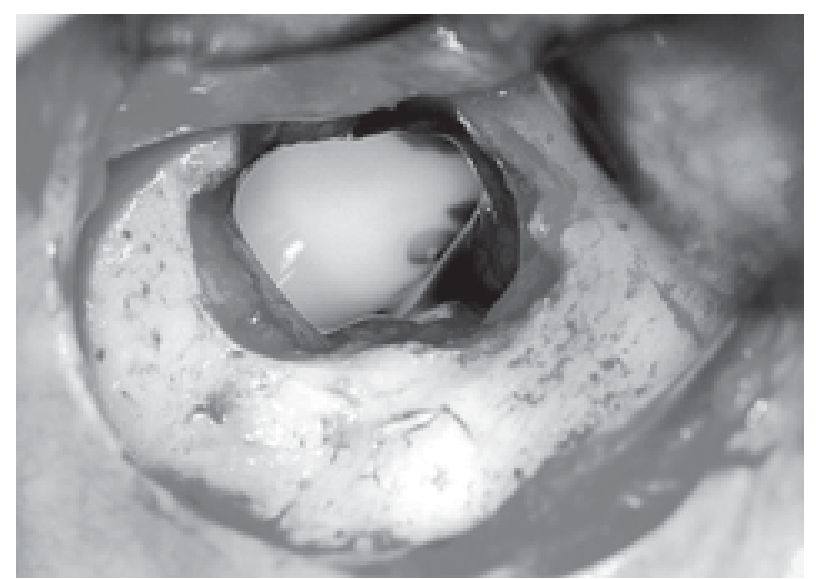

Figure 6. Right maxillary sinus exposed through Caldwell-Luc approach showing a large quantity of purulent secretion.

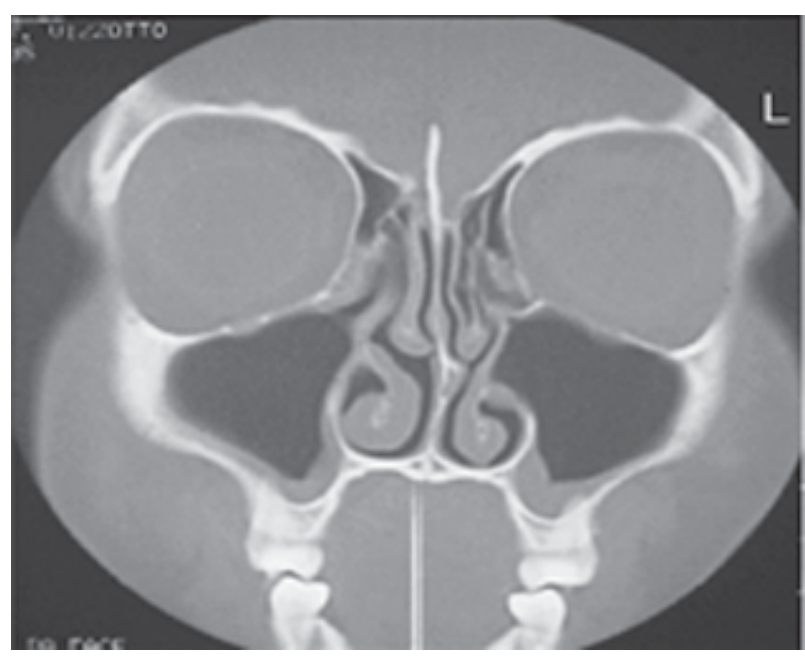

Figure 8. Postoperative frontal CT scan taken 6 months after tooth retrieval, showing a good healing of the right maxillary sinus and etmoidal cells.

indication and choose the most opportune moment for surgery. A clear understanding of the development and movement of the specific third molar is essential for the decision-making process (3). When the roots of a maxillary third molar are only one-half formed, surgery is almost always less difficult to perform because in most cases the patient is less than 20 years old and the tooth is located in a more inferior position.

Surgical removal of impacted third molars is associated with moderated incidence of complications (around 10\%) (6,7). However, less experienced surgeons are naturally expected to have significantly higher incidence of complications than trained, experienced surgeons (8). Among the per and postoperative

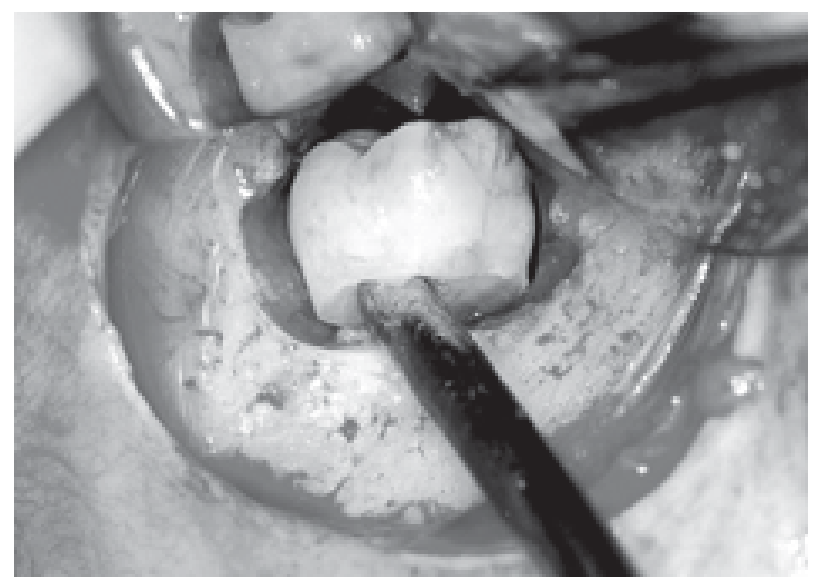

Figure 7. Removal of the displaced tooth through the bone fenestration, by negative pressure of the suction pump.

complications associated with maxillary third molar extraction, the most commonly mentioned in oral surgery textbooks are fractures of the maxillary tuberosity and accidental displacements into the infratemporal fossa or maxillary sinus (1). Excessive apical force during use of elevators and incorrect surgical technique are quoted as the most usual causes of these accidents. Although frequently mentioned, displacement of impacted maxillary third molar is rarely documented in the literature $(1,2)$.

In spite of correct preoperative management, including review of past medical history and clinicalradiographic examination, even experienced surgeons may face a transoperative accident (8). In this case, the patient should be promptly informed about the accident and the possible treatment options should be fully discussed.

In cases of accidental tooth displacement into the maxillary sinus, the most accepted treatment is the removal of the dislodged tooth to prevent future infections (2), preferably during the same surgical procedure, if possible. However, delayed treatment does not always precipitate immediate active sinus disease and sometimes the quiescent asymptomatic interval last several months before an acute infection develops (9). In the case of the patient presented in this paper, the symptoms manifested after a long period (twenty-two months after tooth displacement).

In the event the professional is not experienced and skilled enough to perform the retrieval surgery and/ or the patient is not in physical and/or psychological conditions to support the maxillary sinus surgical intervention within the same session, the dentist must be 
prepared to adequately handle the situation. In the first case, referral to a skilful oral-maxillofacial surgeon is the conduct of choice; in the second case, the procedure for retrieval of the displaced tooth must be postponed to a next date when the patient fells more comfortable. In the meantime between the first and second interventions, the patient must be under antibiotic, analgesic and antiinflammatory medication. As for any surgical procedure involving the maxillary sinus, the conditions of this cavity must be assessed before surgery.

Surgeons performing third molar surgery must not only be skilled and well-trained in this procedure, but also be able to decide whether asymptomatic impacted teeth need to be extracted (3) and which should be the most appropriate patient management in case of complications. Moreover, dental professionals can be faced with medical-legal problems. It is thus of paramount important to keep all case's records, including signed informed consent, $\mathrm{x}$-ray films and others items, as well as to inform the patient immediately about any intraoperative accident occurred during exodontias and discuss which conduct will be followed to solve the unexpected situation.

\section{RESUMO}

Este artigo descreve um caso raro de um terceiro molar superior direito impactado que foi deslocado acidentalmente para o interior do seio maxilar durante exodontia e foi removido cirurgicamente após quase dois anos. O dente foi removido sob anestesia geral, após exposição do seio maxilar pela técnica de Caldwell-Luc. O pós-operatório transcorreu sem complicações. Seis meses após a cirurgia, houve completa recuperação do seio maxilar e a paciente não apresentou qualquer queixa.

\section{REFERENCES}

1. Oberman M, Horowitz I, Ramon Y. Accidental displacement of impacted maxillary third molars. Int J Oral Maxillofac Surg 1986;15:756-758.

2. Patel M, Down K. Accidental displacement of impacted maxillary third molars. Br Dent J 1994,177:57-59.

3. Peterson LJ, Indresano AT, Marciani RD, Roser SM. Oral and Maxillofacial Surgery. Philadelphia: JB Lippincott Company; 1992.

4. Mercier P, Precious D. Risks and benefits of removal of impacted third molars. A critical review of the literature. Int J Oral Maxillofac Surg 1992;21:17-27.

5. Stephens RG, Kogon SL, Reid JA. The unerupted or impacted third molar-a critical appraisal of its pathologic potential. J Can Dent Assoc 1989;55:201-207.

6. Nordenram A. Postoperative complications in oral surgery. Swed Dent J 1983;7:109-114.

7. Goldberg MH, Nemarich AN, Marco WP. Complications after mandibular third molar surgery: a statistical analysis of 500 consecutive procedures in private practice. J Am Dent Assoc 1985;111:277-279.

8. Sisk AL, Hammer WB, Shelton DW, Joy ED: Complications following removal of impacted third molars: the role of experience of the surgeon. J Oral Maxillofac Surg 44: 855859, 1986.

9. Killey HC, Kay LW. Possible sequelae when a tooth or root is dislodged into the maxillary sinus. Br Dent J 1964;21:73-77.

Accepted November 24, 2003 